\title{
Antidepressant treatment among social workers, human service professionals, and non-human service professionals : A multi-cohort study in Finland, Sweden and Denmark
}

\section{Rantonen, $\mathrm{O}$.}

2019-05-01

Rantonen, O, Alexanderson, K, Clark, A J , Aalto , P , Sonden , A, Bronnum-Hansen , H , Hougaard, C O, Rod, N H, Mittendorfer-Rutz, E, Kivimäki, M , Oksanen, T \& Salo , P 2019 , ' Antidepressant treatment among social workers, human service professionals, and non-human service professionals : A multi-cohort study in Finland, Sweden and Denmark ', Journal of Affective Disorders , vol. 250 , pp. 153-162 . https://doi.org/10.1016/j.jad.2019.03.037

http://hdl.handle.net/10138/315577

https://doi.org/10.1016/j.jad.2019.03.037

publishedVersion

Downloaded from Helda, University of Helsinki institutional repository.

This is an electronic reprint of the original article.

This reprint may differ from the original in pagination and typographic detail.

Please cite the original version. 
Research paper

\title{
Antidepressant treatment among social workers, human service professionals, and non-human service professionals: A multi-cohort study in Finland, Sweden and Denmark
}

\author{
O. Rantonen ${ }^{\mathrm{a}, \mathrm{b}, \mathrm{g}, *,}$ K. Alexanderson ${ }^{\mathrm{b}}$, A.J. Clark $^{\mathrm{c}}$, V. Aalto ${ }^{\mathrm{a}}$, A. Sónden ${ }^{\mathrm{b}}$, H. Brønnum-Hansen ${ }^{\mathrm{d}}$, \\ C.Ø. Hougaard ${ }^{\text {d }, ~ N . H . ~ R o d ~}{ }^{c}$, E. Mittendorfer-Rutz ${ }^{b}$, M. Kivimäki ${ }^{a, e, f}$, T. Oksanen ${ }^{a}$, P. Salo ${ }^{a, g}$

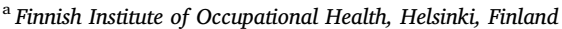 \\ ${ }^{\mathrm{b}}$ Department of Clinical Neuroscience, Division of Insurance Medicine, Karolinska Institutet, Stockholm, Sweden \\ ${ }^{c}$ Department of Public Health, Section of Epidemiology, University of Copenhagen, Copenhagen, Denmark \\ ${ }^{\mathrm{d}}$ Department of Public Health, Section of Social Medicine, University of Copenhagen, Copenhagen, Denmark \\ ${ }^{\mathrm{e}}$ Department of Epidemiology and Public Health, University College London, London, United Kingdom \\ ${ }^{\mathrm{f}}$ Clinicum, Faculty of Medicine, University of Helsinki, Helsinki, Finland \\ ${ }^{\mathrm{g}}$ Department of Psychology, University of Turku, Turku, Finland
}

A R T I C L E IN F O

\section{Keywords:}

Mental disorder

Depression

Epidemiology

Occupation

Social work

Antidepressants

Sickness absence

\begin{abstract}
A B S T R A C T
Background: Social workers have an elevated risk for mental disorders, but little is known about their antidepressant treatment.

Aims: To examine any and long-term antidepressant treatment among social workers in Finland, Sweden and Denmark.

Methods: We linked records from drug prescription registers to three prospective cohorts: the Finnish Public Sector study, years 2006-2011, and nation-wide cohorts in Sweden and Denmark, years 2006-2014, including a total of 1.5 million employees in (1) social work, (2) other social and health care professions, (3) education and (4) office work. We used Cox proportional hazards models to estimate hazard ratios for any and long-term ( $>6$ months) antidepressant treatment among social workers compared to the three reference occupational groups and carried out meta-analyses.

Results: During follow-up, 25\% of social workers had any prescriptions for antidepressants (19-24\% reference occupations) and $20 \%$ for long-term treatment (14-19\% reference occupations). The pooled effects for any and long-term treatment showed that probabilities were $10 \%$ higher in social workers compared to other health and social care professionals and 30\% higher compared to education and non-human service professionals. Probabilities for any treatment in the three countries were relatively similar, but for long-term treatment social workers in Finland had a greater risk compared with other human service professions.

Limitations: There were differences between the cohorts in the availability of data. Specific diagnoses for the antidepressant treatment were not known neither adherence to treatment.

Conclusion: Social workers have a higher risk for any and long-term antidepressant treatment than other human and non-human service professionals.
\end{abstract}

\section{Introduction}

Human service professionals face increasing working life demands. The global changes in working life (e.g. increased workload, time pressure and productivity demands), adverse economic and societal trends at workplaces (e.g. insufficient resources and marketization) have been accompanied with increased job demands due to elevated numbers of customers with complex problems, especially in social work (Blomberg et al., 2015; Mänttäri-van der Kuip, 2014; Welshman, 2017). During the last two decades, increased rates of mental disorders have been reported in human service professionals and, in particular, in social workers who carry out demanding client work (Buscariolli et al., 2018; Lidwall et al., 2018; Rantonen et al., 2017). Social workers were shown to have a 1.5 -fold higher risk of work disability due to mental

\footnotetext{
* Corresponding author.

E-mail address: optran@utu.fi (O. Rantonen).
} 
disorders compared to other human service professionals, such as preschool and special education teachers and psychologists in longitudinal analyses of national health registers in Finland and Sweden (Rantonen et al., 2017). A recent prospective study in Finland, found a 1.2-1.6 times higher likelihood of starting antidepressant treatment among social workers compared to non-human service professionals with similar skill level, particularly among men (Buscariolli et al., 2018). The study was limited to measuring antidepressant use as the first filled prescription during the mean of 15.2 years of follow-up. However, it is not known whether human service professionals vary in the length of antidepressant treatment, a proxy for mental disorder severity. Although societal attitudes could explain country-level variation in antidepressant use (Lewer et al., 2015), no studies have compared antidepressant use in human service professionals between countries.

We used register data on 1.5 million human service professionals from Finland, Sweden and Denmark to examine the use of antidepressant treatment, as any use and long-term use, among social workers compared to other human service (health and education sectors) and non-human service professionals (office workers) with similar skill levels and to do country-level comparison in these occupational groups. Our multi-cohort prospective study further expands on previous literature by including a meta-analysis of results from different cohorts.

\section{Methods}

This study used individual-level data from three Nordic prospective cohort studies: (1) The Finnish Public Sector study (FPS) (Virtanen et al., 2008), (2) a Danish nation-wide cohort of workingaged employees (18-63 years) derived by linking various registers at Statistics Denmark (Thygesen and Ersbøll, 2011), and (3) the Swedish Insurance Medicine All-Sweden project (IMAS) (Lidwall et al., 2018), which covers the working-aged (16-64 years) population in Sweden.

From all cohorts, we included individuals who were employed in health, social care or education sectors or as office workers in 2005. In Finland, individuals had to have at least 6 months of employment based on employers' registers, in Denmark employees had to have received the majority (over 50\%) of their income from work and not unemployment benefits. In Sweden, employees had to have higher income from work and work-related social incomes than old-age pension benefits, to indicate being gainfully employed in working life.

We included participants with a human service occupation (health and social care, and in social work in particular, or education professionals) or a non-human service occupation (office workers) from the Finnish Public Sector study, which includes only occupations in the public sector. We used the same occupational groups, totaling 13 occupations, to include participants from Denmark and Sweden (Appendix 1). In each country, the occupations were categorized according to national version of the International Classification of Occupations (Danmarks Statistik, 2011; Statistics Finland, 2001; Statistics Sweden MIS, 2012).

In the Nordic countries, the required education for social work varies. In Finland, a mandatory master's level academic education with a theoretical focus (5-6 years) is needed. Social workers were identified from occupational titles in employers' registers by an experienced social worker and researcher. In Denmark and Sweden only a bachelor level education (3.5 years) is required. In Denmark, social work is taught at universities, and the training is more practical compared to other Nordic countries. A master's level candidate degree is also available after the bachelor degree. In Denmark, employees with at least 2 years of post-secondary education were selected into the groups of social workers. In Sweden, social workers were defined by the highest education they had completed, and included the two major groups according to appropriate academic educational level (university education in social work or candidate level education in social work). Social workers with low educational levels or non-appropriate training were therefore defined as social work associate professionals in Sweden and Denmark and as such part of other social and health care professions. In Denmark and Sweden we also used annual data for occupation to identify turnover from social work. This was defined as any different occupational code than the occupational code assigned at the beginning of follow-up in 2005. Data was available only on a yearly basis, so the date was estimated as July 1 at the given year. For other occupations, data on turnover was not used. In Finland, such data on turnover was not available.

We excluded employees who were on disability (part-time or full) or old-age pension or had sickness absence of more than 12 months from 2004 to 2005, or were deceased by 1 January 2006. The final sample comprised 1542,095 employees, including 29,096 men and women from Finland; 357,867 from Denmark and 1155,132 from Sweden. Of them, $1.7 \%(N=26,287)$ were social workers, $43 \%(N=663,558)$ health and social care workers, $25.3 \%(N=389,640)$ workers in education and $30.0 \%(N=462,610)$ non-human service professions. The latter 3 occupational groups were used as reference groups.

\section{Ethics statement}

The approval for the study was obtained from the Ethics Committee of the Helsinki-Uusimaa Hospital District in Finland, the Regional Ethical Review Board of Stockholm in Sweden, and the Data Protection Agency in Denmark.

\section{Outcome measures}

We obtained data on prescription date and number of defined daily doses (DDD) for prescription drugs with the ATC-code N06A (antidepressants) (WHOCC, 2012) from the beginning of 2004 to the end of 2011 in Finland, 2014 in Sweden and 2016 in Denmark. Prescription data was derived from the Prescription Register held by Statistics Finland, the Danish National Prescription Registry (Kildemoes et al., 2011) and the Swedish Drug Prescription Register (Wettermark et al., 2013).

We estimated the probability of use of antidepressant treatment as: 1) any treatment during the follow-up, defined as at least one purchase during follow-up (the first date), and 2) long-term antidepressant use, defined as using antidepressants for more than 6 months (>179 DDD) during a 12 month period (Magnusson Hanson et al., 2013; Thielen et al., 2009). In Finland and Denmark, the $>179$ DDD treatment during 12 months was estimated by scanning each prescription and the 365 days before that. In Sweden, the cutoff was half of that, $>89$ DDD treatment during 6 months, due to data availability for only 6 months retrospectively at the baseline (from June 2005). If the rate accumulated over the cutoff, that index prescription date was defined as the event date.

\section{Covariates}

In all cohorts, covariates included age, sex, area of residence, receiving all-cause sickness absence benefits over 14 days in a 2-year period prior to baseline, and in- and/or outpatient treatment of mental disorders or chronic somatic diseases up to 10 years prior to baseline (only inpatient data in Finland). In Denmark and Sweden, we also included marital status (no data available in Finland). Area of residence was categorized as (1) capital region and (2) other regions in Finland and Denmark and to (1) big city (Stockholm, Gothenburg and Malmo), 


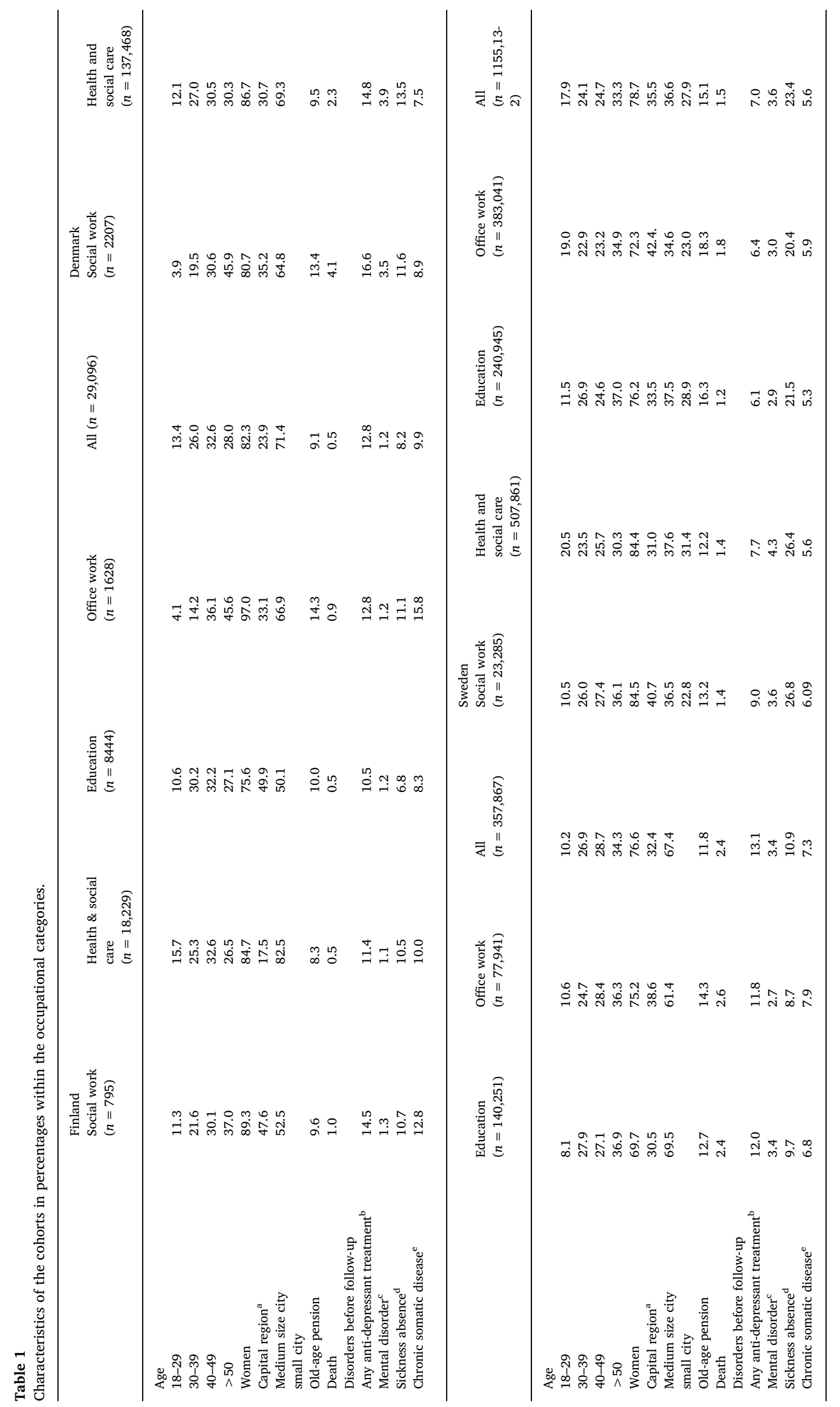


(2) medium size city ( $>90000$ inhabitants within $30 \mathrm{~km}$ distance), or (3) small city in Sweden city ( $\leq 90000$ inhabitants within $30 \mathrm{~km}$ distance).

We included two health-related covariates, which were specified as dichotomous variables (yes/no). First, chronic somatic diseases (cardiovascular disease, diabetes, rheumatoid arthritis, prevalent hypertension, asthma or other chronic obstructive lung disease), malignant tumors, or hospitalization due to mental disorders before baseline were included between 1995 and 2005, with slightly different data availability in cohorts. Chronic somatic diseases was available from 1995 (2000 in Sweden), malignant tumors from 2000 (1995 in Denmark) and mental disorders from 1995 (2001 in Sweden; no outpatient data in Finland). Second, we included all-cause sickness absence benefit spells (after the employer compensated period) in 2004-2005. In Finland this was $\geq 14$ days duration of benefits, and in Denmark and Sweden, sum of sickness benefit days $\geq 14$ days in 2004 or 2005, even if spells were separate.

\section{Statistical analyses}

All analyses were done separately in each cohort from baseline in 2006 to end of follow-up, i.e., 2011 in Finland, 2016 in Denmark and 2014 in Sweden. To determine the probability of antidepressant treatment we used Cox proportional hazards models to estimate the HR for medication use in social workers compared to each of the reference occupation groups separately, for initiation of any use and long-term use, respectively. Individuals were censored at the time of antidepressant treatment (any treatment or long-term treatment), selection out of social work (in Denmark), death or end of follow-up. In the models we controlled first for age and sex, and then additionally to marital status (no data in Finland), area of residence, chronic somatic diseases or in- and outpatient treatment for mental disorders in 1995-2005 (in Finland only inpatient treatment; in Sweden years 2001-2005) and sickness absence benefits due to any cause in 2004-2005.

Results for each occupational comparison were pooled from the cohorts with fixed effects meta-analysis (Nikolakopoulou et al., 2014). Heterogeneity was assessed with the $\mathrm{I}^{2}$ statistic. We did the main analysis with SAS (version 9.2; 9.3 in Denmark) and meta-analysis in STATA (version 14).

Additional analyses were carried out stratified by sex in Denmark and Sweden and in Finland analyses were done for female employees only due to a low number of cases among male employees.

\section{Results}

Table 1 shows the characteristics of the study population stratified by the occupational groups in each country. In the entire sample, approximately two-thirds in each occupational group were women with the exception of Finland where $97 \%$ of non-human service professionals were women. In Finland, employees in health and social care professions were generally younger than other groups. In Denmark, the age structure was relatively similar in all occupational groups, except for social work where employees over 50 years were more frequent. In Sweden, social and education workers had higher proportions of older employees.

During the year prior to baseline, antidepressants were prescribed to $12.8 \%$ of the employees in the FPS cohort, $13.1 \%$ in the Danish cohort and $7.0 \%$ in the Swedish cohort, and most commonly among social workers (19.4\% in Finland; 16.6\% in Denmark; 9.0\% in Sweden). In- or outpatient treatment due to mental disorders was recorded for $1.2 \%$ of employees in Finland (only inpatient) and 3.4\% in Denmark and 3.6\% in Sweden, with the rates being relatively equal between occupations. A chronic somatic disease was recorded for $9.9 \%$ of employees in Finland, $7.3 \%$ in Denmark and $5.6 \%$ in Sweden. Rates of sickness absence exceeding 14 days were $8.2 \%$ in Finland, $10.9 \%$ in Denmark and $23.4 \%$ in Sweden, with the highest rates for social workers and other health and social care professionals and non-human service professionals in Finland.

During follow-up, in total $25 \%$ of social workers had any prescriptions for antidepressants (19-24\% in reference occupations; Table 2). In meta-analysis, the probability for any treatment was more than $30 \%$ higher compared to education and non-human service professionals and about $10 \%$ higher compared to other health and social care professionals. In the meta-analysis, the Swedish cohort was weighted heavily and thus the results in Finland and Denmark had a minor impact on the pooled estimates. Heterogeneity was small, except for the comparisons with non-human service professionals in Denmark $\left(\mathrm{I}^{2}=91.2 \%\right)$. In country-specific comparisons, social workers had the highest probability for any antidepressant treatment in all countries (Table 2), except in Finland in the fully adjusted model the probability was higher only compared to education professionals (HR 1.26, 95\% CI 1.07-1.47). In Denmark, HRs varied between 1.16 (95\% CI 1.05-1.28) and 1.66 (95\% CI 1.51-1.83) and HR was the highest compared to non-human service professionals. In Sweden, the HRs varied between 1.08 (95\% CI 1.05-1.11) and 1.32 (95\% CI 1.29-1.36).

In total, $20 \%$ of social workers had over 179 DDDs of antidepressant prescriptions within 1 year (i.e., long-term treatment) (14-19\% in reference occupations; Table 2). In meta-analysis, the probability for long-term treatment remained similar to those for any treatment (Table 2). Heterogeneity was small, except for the comparisons with non-human service professionals in Denmark $\left(\mathrm{I}^{2}=57.1 \%\right)$, and comparisons to health and social care professionals in Finland $\left(\mathrm{I}^{2}=49.0 \%\right)$. In country-specific comparisons, social workers had the highest probability for long-term antidepressant treatment in all countries (Table 2). In Finland, the probabilities were higher compared to all occupational groups, with the highest probability being observed in comparison with educational professionals (HR 1.49, 95\% CI 1.23-1.81). In Denmark, social workers had a higher probability compared to educational professionals (HR 1.26; 95\% CI 1.12-1.42) and non-human service professionals (HR 1.55, 95\% CI 1.37-1.75), but not with other health and social care professionals. In Sweden, social workers had a higher probability compared to all occupations and the HRs varied between 1.09 (95\% CI $1.06-1.12$ ) and 1.35 (95\% CI $1.31-1.39$ ).

In stratified analyses, a higher percentage of female than male employees had any and long-term antidepressant treatment (Table 3). In Denmark, male social workers had higher hazards than female employees in all occupational comparisons for any treatment. These differences decreased in the models for long-term treatment, and male social workers had only slightly higher hazards compared to nonhuman service professionals. In Sweden male social workers had higher hazards than women in comparisons to education professionals and non-human service professionals, for both any and long-term antidepressant treatment. In Finland, the frequency of male social workers was small and wide confidence intervals limited conclusions. Female social workers had a higher likelihood of any treatment compared with education professionals, and higher likelihood of long-term treatment in all occupational comparisons.

\section{Discussion}

In this large multi-cohort study social workers were at a heightened 


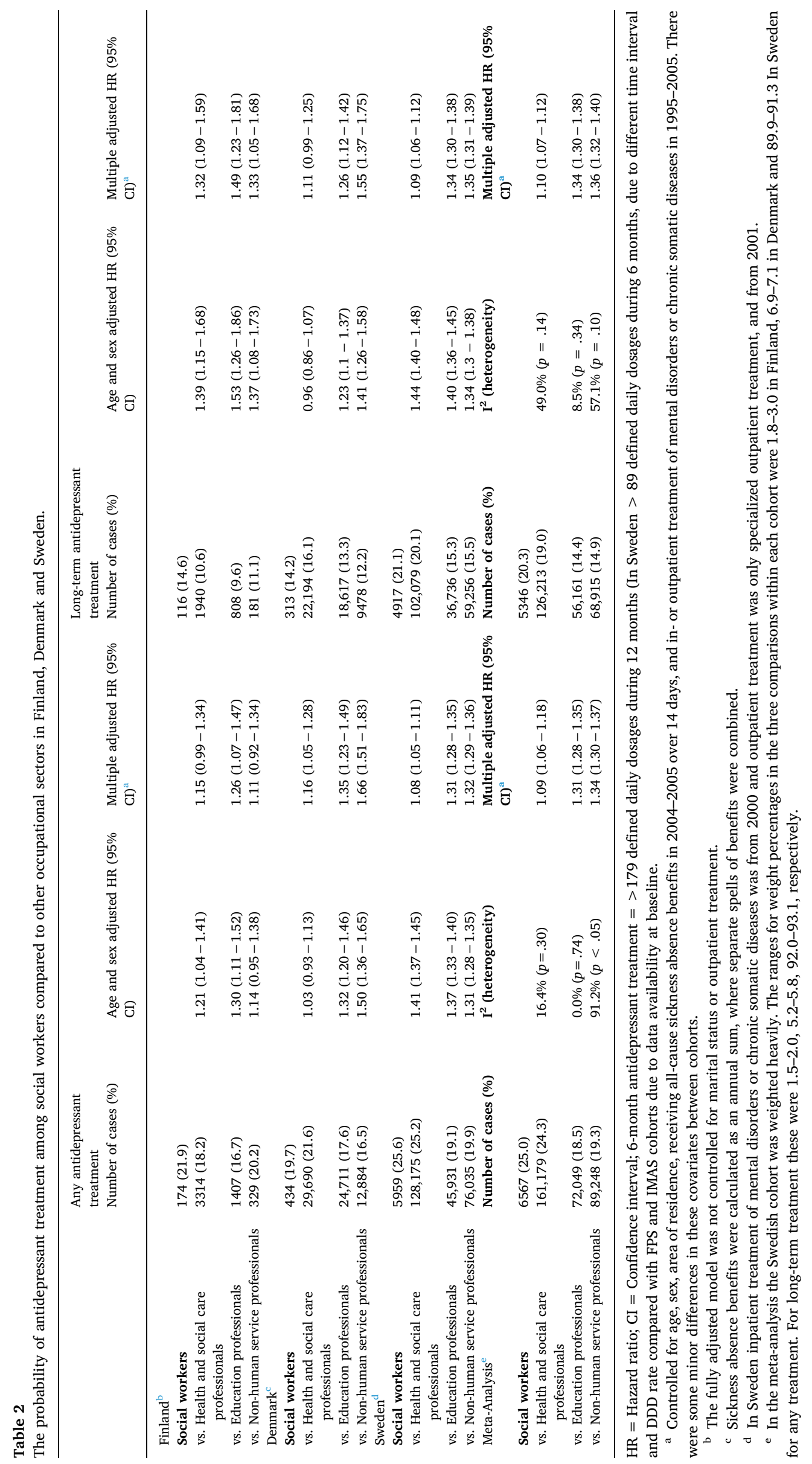


probability of antidepressant treatment and long-term antidepressant treatment compared to human service and non-human service professionals, and the results were largely similar between countries. These results are in line with previous studies of the increased risk of mental disorders among social workers (Buscariolli et al., 2018; Lidwall et al., 2018; Rantonen et al., 2017). We contribute to existing knowledge on antidepressant treatment in human service professionals with a comparative Nordic perspective including findings from two large nationwide cohorts and the Finnish Public Sector Study and combination of those results in a meta-analysis. Meta-analysis provides a synthesis of the effect sizes with appropriate weighting for studies with different sample sizes (Nikolakopoulou et al., 2014). In our study, the metaanalyses are mainly driven by the results from the Swedish cohort, which constitute the largest sample. We also measured long-term antidepressant treatment in addition to any treatment, and compared the probability among social workers specifically, to multiple human service occupations and non-human service professionals.

This is to our knowledge the first study to investigate long-term antidepressant treatment and the first replication of probability of any antidepressant treatment among social workers compared to other human service occupations. The only previous study used a random population-based sample of over 700,000 Finnish employees and showed similar results to our meta-analysis regarding any antidepressant treatment among Finnish social workers $(N=5480)$ compared to non-human service professionals with similar skill level (Buscariolli et al., 2018). We also compared social workers to other human service professionals and found that the increased probability of any or long-term antidepressant treatment was not restricted to comparison with non-human service professionals, although the probability was less profound compared with other health and social care professionals. The health and social care professionals group included nurses and home care assistants, that have been identified as risk groups for mental disorders as well (Buscariolli et al., 2018; Wieclaw et al., 2006). Also, job demands are higher in health and social care professions in general than in education and non-human service professions (Borritz et al., 2006; Rugulies et al., 2009). In the Finnish sample, social workers had a higher probability of any treatment was higher only compared with education professionals, but for long-term treatment it was higher compared to all occupations.

Similar associations were observed in Denmark and Sweden, but there were some differences. When comparing results from all cohorts, social workers had a higher probability of any antidepressant treatment and the probabilities were relatively similar between cohorts. However, these probabilities were slightly lower in Denmark and remained stable in Sweden for long-term treatment, whereas in Finland they became stronger by $15-20 \%$ percentage points. Finally, in Denmark the probabilities for both outcomes among social workers were much higher compared with non-human service professionals than in other countries. These results were synthesized in meta-analyses that showed similar hazard ratios for any and long-term treatment.

In contrast, previous evidence suggests that emotional demands are associated with long-term treatment more strongly than with any treatment (Magnusson Hanson et al., 2013), and social work involves more emotional demands than most human service occupations (Borritz et al., 2006). However, in Finland hazards ratios were elevated for long-term treatment and there is some evidence that Finnish social workers experience higher client load, job strain and more conflicting demands than social workers in other Nordic countries (Blomberg et al., 2015). In Finland, social workers have a higher education than in Denmark and Sweden, which may lead to greater responsibilities at work. Some studies suggest that organization of social services in
Finland and lack of resources may be more problematic in Finland than other Nordic countries (Blomberg et al., 2015; Welshman, 2017). On the other hand, the fact that the Finnish data were significantly smaller and included only public sector employees may have contributed to the differences in results.

Another explanation may include minor differences in the covariates between the countries. Furthermore, rates of antidepressant treatment were lower and rates of sickness absence were higher in Sweden compared to Finland and Denmark. This may be related to cultural differences in treatment policies, social insurance benefits or the organization of health care, which may also impact the results (Blomberg et al., 2015; Wahlbeck et al., 2011).

Our findings from sex-stratified analyses add to previous evidence showing that especially male social workers had a higher likelihood of any antidepressant treatment than male non-human service professionals (Buscariolli et al., 2018). In our study this was true in comparison to educational professionals as well, regarding both outcomes in the Danish and Swedish data. Buscariolli et al. (2018) attributed this gender-specific risk to working in a female-dominated sector as a gender minority, which could increase the likelihood of treating depression symptoms with antidepressant medication as an occupationspecific coping method (Buscariolli et al., 2018). However, in our study social workers had no gender-specific risks in comparison to other health and social care professionals. Thus, the gender-specific risk may be related to working in health and social care professions as a male employee, rather than a female dominated sector. The stigma of mental disorders is particularly high among male health and social care professionals (Clement et al., 2015) and thus it may hinder help-seeking behaviors, decrease the likelihood of early detection and increase antidepressant use as an organization-specific coping mechanism (Buscariolli et al., 2018). High-risk occupations in this sector may include also social care associate professionals, nurses and home care assistants (Buscariolli et al., 2018; Lidwall et al., 2018; Wieclaw et al., 2006).

Two plausible explanations have been suggested to underlie the higher risk of mental disorders among social workers: (1) high job stress due to work-related risk factors and (2) selection of vulnerable employees into social work (Madsen et al., 2012). A previous meta-review supports the link between work-related risk factors and mental disorders (Harvey et al., 2017). Social work involves multiple work-related risk factors (Mcfadden, 2015; Rugulies et al., 2009; van Vegchel, 2004), such as emotional demands (Borritz et al., 2006; Magnusson Hanson et al., 2013; van Vegchel, 2004), risk of threats and violence (Wieclaw et al., 2006b), role conflicts (Blomberg et al., 2015) and moral distress (i.e., inability to make decisions according to own values) (Mänttäri-van der Kuip, 2016). Many of the risk factors are shared by other human service professions as well, but are likely more prevalent in social work (Borritz et al., 2006; Mcfadden, 2015; Rugulies et al., 2009). Social workers have high responsibility over decision making in clients' often complicated and chronic life situations (e.g. marginalization, multiple or cross-generational problems) (Blomberg et al., 2015). Their tasks include creating action plans to improve their clients' life situations by allocating resources, and counseling the client in implementing the plan (Danmarks Statistik, 2011; Statistics Finland, 2001; Statistics Sweden MIS, 2012). This balancing between the roles of a helper and street level bureaucrat creates role conflicts. The cumulative effect of job demands increases the risk of mental disorders in social work and long-term exposure can lead to mental disorders (Madsen et al., 2016; Madsen, 2014; van Vegchel, 2004). The hypothesis on selection of vulnerable employees into social work, (Madsen et al., 2012; Mcfadden, 2015; West, 2015) has been supported by studies 


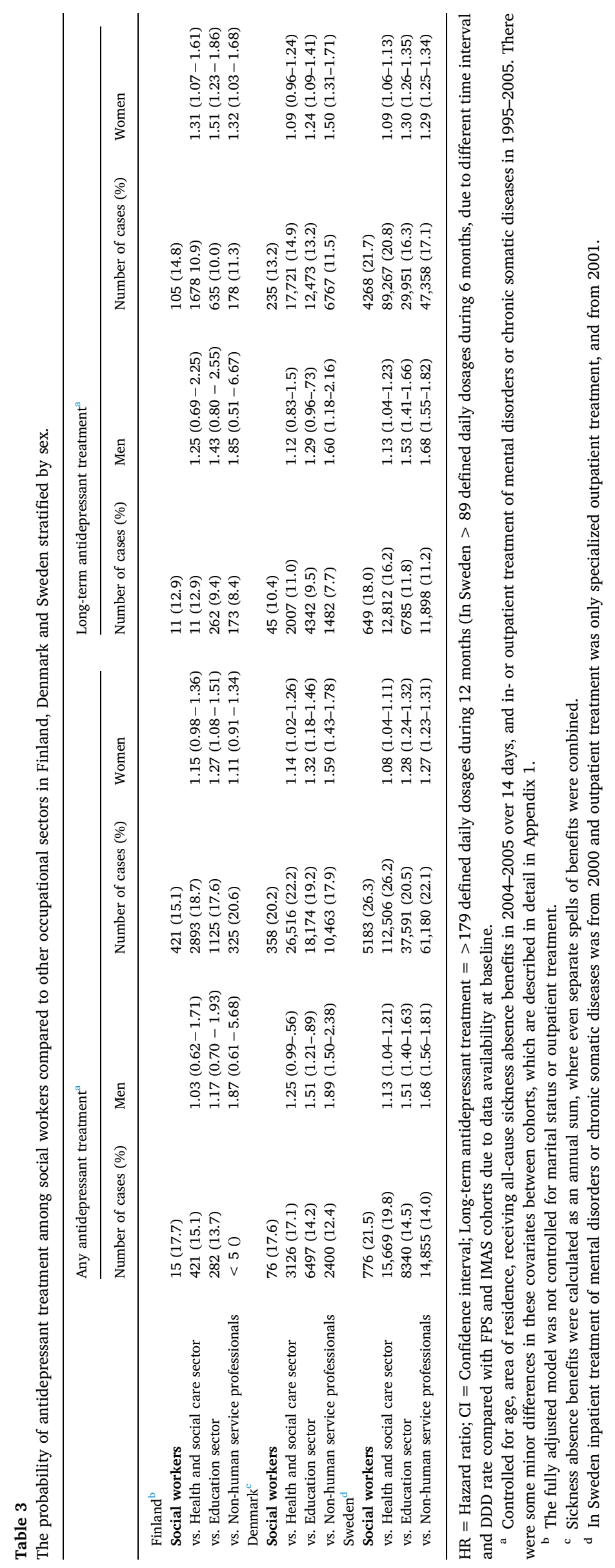


showing, e.g., that social workers may often have a personal history of assuming a caretaker role in childhood due to family dynamics and conditions (i.e., parentification), anxious attachment style or traumatic experiences, which are associated with lower resilience and increased burnout (Mcfadden, 2015; Pooler et al., 2008; West, 2015). However, only few high-quality longitudinal studies have tried to tackle the selection hypothesis (Madsen et al., 2012; Pooler et al., 2008; West, 2015).

\section{Strengths and limitations}

The Nordic countries provide a unique possibility for register-based research on mental health with reliable data on pharmacological treatment (Wettermark et al., 2013). The strengths of the register data used in this study were good representativeness, low attrition and a total coverage of the working aged population in Sweden and Denmark, and a wide coverage of public sector employees in Finland. Registerbased studies do not have the limitations of selective drop-out. However, when using register data for mental disorders, the issue of validity of diagnosis is a central concern (Allebeck, 2009). Data on antidepressant prescriptions is commonly used as an objective measure for mental disorders that require medical treatment (Thielen et al., 2009). Antidepressants are a recommended and common treatment for moderate to severe major depressive disorder and a treatment option in mild major depression (Cleare et al., 2015). For higher validity, we used a specific dose to identify individuals with depression (Thielen et al., 2009). Mental health problems are a major cause for attrition in questionnaire-based studies and thus register-based studies are important for accumulating reliable findings about the predictors of mental disorders (Goldberg et al., 2006).

The validity of register data on antidepressants as an indicator of depression may, however, be compromised because antidepressants are commonly prescribed for other conditions too, such as anxiety, sleep disorders, chronic pain and in response to stressful life events. Our data did not contain information on the diagnosis for which medication was prescribed, and thus, strong conclusions about the diagnosis based on prescription cannot be drawn from the data alone (Demyttenaere et al., 2008). Twelve-month prevalence of depression among antidepressant users is only $30-35 \%$ and lower among short-term users (Demyttenaere et al., 2008). Furthermore, we had no data on treatment adherence.

Seeking help for mental health problems such as depression is associated with age, educational level, social support and physical health (Thielen et al., 2009). In human service professions, the degree of knowledge about mental disorders and stigma-related attitudes affect help-seeking behaviors and antidepressant use (Clement et al., 2015), and this may vary between occupations. For example, beliefs about incompetence of professional helpers with mental disorders may decrease the likelihood of seeking help among healthcare and particularly mental health care professionals. On the other hand, health and social care professionals may have more accurate information on the treatment options and their efficacy.

There were some differences in the covariates between the cohorts.
All-cause sickness absence was measured differently in Finland than in the other cohorts, all-cause sickness absence in 2004-2005 was defined as having any sickness absence spell (i.e., after the employer compensated period) for over 14 days. In the two other cohorts it was defined as having a sum of more than 14 days of sickness absence in 2004 or 2005, even if the benefit spells were separate. Also, in the Finnish cohort we only had data on inpatient treatment and no outpatient treatment, which excludes most cases of common mental disorders given that only the most severe cases are hospitalized, which further affects the comparability of the Finnish results (Allebeck, 2009). However, despite these differences the results were relatively similar in all cohorts. Finally, the Finnish sample covered only municipal employees and the Swedish and Danish cohorts were nation-wide. This was evident for example in that the proportion of non-human service professionals was $21.8 \%$ and $33.2 \%$ percent in Denmark and Sweden and only $5.7 \%$ in Finland. It may thus be that the demographics and job characteristics among non-human service professionals were relatively different in Finland compared to Denmark and Sweden in our study.

\section{Conclusions}

Social workers had a higher probability of any and long-term antidepressant treatment in most comparisons to other human service and non-human service occupations in Finland, Denmark, and Sweden. The results indicate that social work is a highly demanding occupation, which needs to be taken into account in education, leadership and management, and health promotion at the workplace. Research is needed on effective interventions to reduce the increased risk of mental disorders in social work.

\section{Author statement}

Contributors

All authors have contributed to the manuscript. OR was the main investigator and had a role in all analyses and the completion of the manuscript. All authors have contributed to the writing of the manuscript. PS, TO, VA and MK contributed to analyses in Finland. NHR, ACL, HB-H and CH contributed to analyses in Denmark. KA, EM-R and AS contributed to analyses in Sweden.

Role of the funding source

Dr. Kivimäki reports grants from Academy of Finland (311492), during the conduct of the study. Authors report no other funding.

\section{Conflicts of interest}

None.

\section{Acknowledgments}

None.

Appendix

Table A1. 
Allebeck, P., 2009. The use of population based registers in psychiatric research. Acta Psychiatr. Scand. 120, 386-391.

Blomberg, H., Kallio, J., Kroll, C., Saarinen, A., 2015. Job stress among social workers: determinants and attitude effects in the Nordic countries. Br. J. Social Work 45, 2089-2105.

Borritz, M., Rugulies, R., Bjorner, J.B., Villadsen, E., Mikkelsen, O.A., Kristensen, T.S., 2006. Burnout among employees in human service work: design and baseline findings of the PUMA study. Scand. J. Public Health 34, 49-58.

Buscariolli, A., Kouvonen, A., Kokkinen, L., Halonen, J.I., Koskinen, A., Väänänen, A., 2018. Human service work, gender and antidepressant use: a nationwide registerbased 19-year follow-up of 752683 women and men. Occup. Environ. Med. 75, 401.

Cleare, A., Pariante, C.M., Young, A.H., Anderson, I.M., Christmas, D., Cowen, P.J., Dickens, C., Ferrier, I.N., Geddes, J., Gilbody, S., Haddad, P.M., Katona, C., Lewis, G., Malizia, A., McAllister-Williams, R.H., Ramchandani, P., Scott, D., Taylor, D., Uher, R., the members of the Consensus Meeting, 2015. Evidence-based guidelines for treating depressive disorders with antidepressants: a revision of the 2008 British Association for Psychopharmacology guidelines. J. Psychopharmacol. 29, 459.

Clement, S., Schauman, O., Graham, T., Maggioni, F., Evans-Lacko, S., Bezborodovs, N., Morgan, C., Rüsch, N., Brown, J.S.L., Thornicroft, G., 2015. What is the impact of mental health-related stigma on help-seeking? A systematic review of quantitative and qualitative studies. Psychol. Med. 45, 11-27.

Danmarks Statistik, 2011. DISCO-08 - Danmarks Statistiks fagklassifikation. 1.

Demyttenaere, K., Bonnewyn, A., Bruffaerts, R., De Girolamo, G., Gasquet, I., Kovess, V., Haro, J.M., Alonso, J., 2008. Clinical factors influencing the prescription of antidepressants and benzodiazepines. J. Affective Disord. 110, 84-93.

Goldberg, M., Chastang, J.F., Zins, M., Niedhammer, I., Leclerc, A., 2006. Health problems were the strongest predictors of attrition during follow-up of the GAZEL cohort. J. Clin. Epidemiol. 59, 1213-1221.

Harvey, S.B., Modini, M., Joyce, S., Milligan-Saville, J.S., Tan, L., Mykletun, A., Bryant, R.A., Christensen, H., Mitchell, P.B., 2017. Can work make you mentally ill? A systematic meta-review of work-related risk factors for common mental health problems. Occup. Environ. Med. 74, 301-310.

Kildemoes, H.W., Sørensen, H.T., Hallas, J., 2011. The Danish National Prescription Registry. Scand. J. Public Health 39 (Suppl 7), 38-41.

Lewer, D., O'Reilly, C., Mojtabai, R., Evans-Lacko, S., 2015. Antidepressant use in 27 European countries: associations with sociodemographic, cultural and economic factors. Br. J. Psychiatry 207, 221-226.

Lidwall, U., Bill, S., Palmer, E., Olsson Bohlin, C., 2018. Mental disorder sick leave in Sweden: a population study. Work 59, 259-272.

Madsen, I.E.H., Nyberg, S.T., Magnusson Hanson, L.L., Ferrie, J.E., Ahola, K., Alfredsson, L., Batty, G.D., Bjorner, J.B., Borritz, M., Burr, H., Chastang, J., de Graaf, R., Dragano, N., Hamer, M., Jokela, M., Knutsson, A., Koskenvuo, M., Koskinen, A., Leineweber, C., Niedhammer, I., Nielsen, M.L., Nordin, M., Oksanen, T., Pejtersen, J.H., Pentti, J., Plaisier, I., Salo, P., Singh-Manoux, A., Suominen, S., ten Have, M., Theorell, T., Toppinen-Tanner, S., Vahtera, J., Väänänen, A., Westerholm, P.J.M., Westerlund, H., Fransson, E.I., Heikkilä, K., Virtanen, M., Rugulies, R., Kivimäki, M., for the IPD-Work Consortium., 2016. Job strain as a risk factor for clinical depression: systematic review and meta-analysis with additional individual participant data. Psychol. Med. 47, 1342-1356.

Madsen, I.E.H., Aust, B., Burr, H., Carneiro, I.G., Diedrichsen, F., Rugulies, R., 2012. Paid care work and depression: a longitudinal study of antidepressant treatment in female eldercare workers before and after entering their profession. Depress. Anxiety 29, 605.

Madsen, I.E.H., Magnusson Hanson, L.L, Rugulies, R., Theorell, T., Burr, H., Diderichsen, F., Westerlund, H., 2014. Does good leadership buffer effects of high emotional demands at work on risk of antidepressant treatment? A prospective study from two Nordic countries. Soc. Psychiatry Psychiatr. Epidemiol. 49, 1209.

Magnusson Hanson, L.L., Madsen, I.E., Westerlund, H., Theorell, T., Burr, H., Rugulies, R., 2013. Antidepressant use and associations with psychosocial work characteristics. A comparative study of Swedish and Danish gainfully employed. J. Affect. Disord. $149,38$.

Mänttäri-van der Kuip, M., 2016. Moral distress among social workers: the role of insufficient resources. Int. J. Social Welfare 25, 86-97.

Mänttäri-van der Kuip, M., 2014. The deteriorating work-related well-being among statutory social workers in a rigorous economic context. Eur. J. Social Work 17, 672-688.

Mcfadden, P., 2015. Resilience and burnout in child protection social work: individual and organisational themes from a systematic literature review. Br. J. Social Work 45, 1546-1563.

Nikolakopoulou, A., Mavridis, D., Salanti, G., 2014. Demystifying fixed and random effects meta-analysis. Evid Based Mental Health. 17, 53-57.

Pooler, D.K., Siebert, D.C., Faul, A.C., Huber, R., 2008. Personal history and professional impairment. Adm. Soc. Work. 32, 69-85.

Rantonen, O., Alexanderson, K., Pentti, J., Kjeldgård, L., Hämäläinen, J., Mittendorfer Rutz, E., Kivimäki, M., Vahtera, J., Salo, P., 2017. Trends in work disability with mental diagnoses among social workers in Finland and Sweden in 2005-2012. Epidemiol. Psychiatr. Sci. 26, 644-654.

Rugulies, R., Aust, B., Siegrist, J., von dem Knesebeck, O., Bultmann, U., Bjorner, J.B., Burr, H., 2009. Distribution of effort-reward imbalance in Denmark and its prospective association with a decline in self-rated health. J. Occup. Environ. Med. 51, 870-878.

Statistics Finland, 2001. Classification of Occupations 2001. Statistics Finland, Helsinki. Statistics Sweden MIS, 2012. SSYK 2012 Swedish Standard Classification of Occupations 
2012.

Thielen, K., Nygaard, E., Andersen, I., Rugulies, R., Heinesen, E., Bech, P., Bültmann, U., Diderichsen, F., 2009. Misclassification and the use of register-based indicators for depression. Acta Psychiatr. Scand. 119, 312-319.

Thygesen, L.C., Ersbøll, A.K., 2011. Danish population-based registers for public health and health-related welfare research: introduction to the supplement. Scand. J. Public Health 39 (Suppl 7), 8.

van Vegchel, N., de Jonge, J., Söderfeldt, M., Dormann, C., Schaufeli, W., 2004. Quantitative versus emotional demands among Swedish human service employees: moderating effects of job control and social support. Int. J. Stress Manage. 11, 21-40.

Virtanen, M., Pentti, J., Vahtera, J., Ferrie, J.E., Stansfeld, S.A., Helenius, H., Elovainio, M., Honkonen, T., Terho, K., Oksanen, T., Kivimäki, M., 2008. Overcrowding in hospital wards as a predictor of antidepressant treatment among hospital staff. Am. J. Psychiatry. 165, 1482-1486.

Wahlbeck, K., Westman, J., Nordentoft, M., Gissler, M., Laursen, T.M., 2011. Outcomes of Nordic mental health systems: life expectancy of patients with mental disorders. Br. J. Psychiatry. 199, 453-458.

Welshman, J., 2017. Troubles and the family: changes and continuities since 1943. Soc.
Policy Soc. 16, 109-117.

West, A.L., 2015. Associations among attachment style, burnout, and compassion fatigue in health and human service workers: a systematic review. J. Hum. Behav. Soc. Environ. 25, 571-590.

Wettermark, B., Zoëga, H., Furu, K., Korhonen, M., Hallas, J., Nørgaard, M., Almarsdottir A., Andersen, M., Andersson Sundell, K., Bergman, U., Helin-Salmivaara, A., Hoffmann, M., Kieler, H., Martikainen, J., Mortensen, M., Petzold, M., WallachKildemoes, H., Wallin, C., Sørensen, H., 2013. The Nordic prescription databases as a resource for pharmacoepidemiological research—a literature review. Pharmacoepidemiol. Drug Saf. 22, 691-699.

WHOCC, 2012. Guidelines for ATC classification and DDD assignment 2013.

Wieclaw, J., Agerbo, E., Mortensen, P.B., Bonde, J.P., 2006. Risk of affective and stress related disorders among employees in human service professions. Occup. Environ. Med. 63, 314-319.

Wieclaw, J., Agerbo, E., Mortensen, P.B., Burr, H., Tüchsen, F., Bonde, J.P., 2006b. Work related violence and threats and the risk of depression and stress disorders, J. Epidemiol. Community Health 60, 771-775. 